\title{
PEMANFAATAN LIMBAH PLASTIK SEBAGAI ENERGY ALTERNATIF
}

\author{
Arif Setyo Nugroho \\ Fakultas Teknik, Program Studi Teknik Mesin \\ Akademi Teknologi Warga Surakarta \\ Email: arif.snug@yahoo.co.id \\ Rahmad \\ Program Studi Teknik Elektro \\ Akademi Teknologi Warga Surakarta \\ Email: mangmamat@yahoo.com \\ Suhartoyo \\ Program Studi Teknik Mesin \\ Akademi Teknologi Warga Surakarta \\ Email: mashartoyo@yahoo.com
}

\begin{abstract}
ABSTRAK
Tujuan penelitian ini adalah untuk mengolah sampah plastik jenis Polypropelyn (PP), pengolahan dengan cara pyrolysis dengan variasi temperature reactor $300{ }^{\circ} \mathrm{C}, 350^{\circ} \mathrm{C}$ dan $400^{\circ} \mathrm{C}$. reactor berbentuk tabung berdiameter $40 \mathrm{~cm}$ tinggi $60 \mathrm{~cm}$ tertutup rapat tanpa udara. Pemasan diluar reactor. Pendinginan menggunakan system kondensor. Pyrolisis pada suhu rendah plastik PP akan menghasilkan minyak sedikit. Plastik PP memiliki struktur ikatan kristal teratur, lebih sulit terdekomposisi jika dibandingkan dengan plastik PE yang memiliki struktur rantai yang panjang dan bercabang. Hasil pengujian didapat bahwa pada suhu $400^{\circ} \mathrm{C}$ jumlah minyak, gas, dan padatan yang dihasilkan berturut-turut sebesar $52 \%$, , $15 \%$ dan $33 \%$. Minyak yang dihasilkan lebih banyak dibandingkan dengan temperature reactor $200{ }^{\circ} \mathrm{C}$. Hasil pada suhu $200^{\circ} \mathrm{C}$ jumlah minyak, gas, dan padatan yang dihasilkan berturut-turut sebesar $30 \%$, $10 \%$, dan $60 \%$. Rata- rata waktu penyalaan generator berbahan bakar gasolin adalah 9,25 menit dengan berbagai macam variasi pembebanan. Waktu terlama penyalaan generator adalah 11.09 menit dengan bahan bakar campuran gasolin + minyak pyrolisis (temperatur $300^{\circ} \mathrm{C}$ ) dan paling boros adalah 9.02 menit berbahan bakar $100 \%$ minyak hasil pyrolisis.
\end{abstract}

Kata kunci: pyrolisis, temperatur, minyak, PP, generator.

\begin{abstract}
The aim research is to process Polypropelen $(P P)$ type plastic waste, processing with pyrolysis with variation of temperature reactor $300^{\circ} \mathrm{C}, 350^{\circ} \mathrm{C}$ and $400^{\circ} \mathrm{C}$. tubular reactor with diameter $40 \mathrm{~cm}$ height 60 $\mathrm{cm}$ tightly closed without air. Packaging outside reactor. Cooling using condenser system. Pyrolysis at low temperature PP plastic will produce a little oil. PP plastics have a regular crystal bond structure, more difficult to decompose when compared to PE plastics that have long and branched chain structures. Test results showed that at 4000C the amount of oil, gas, and solids produced respectively 52\%, 15\% and $33 \%$. The oil produced is much higher than the reactor temperature of $300{ }^{\circ} \mathrm{C}$. The results at $300^{\circ} \mathrm{C}$ of the amount of oil, gas, and solids produced respectively by 30\%, 10\%, and 60\%. The average ignition time of a gasoline-fueled generator is 9.25 minutes with various loading variations. The longest time to start the generator is 11.09 minutes with fuel gasoline mix + pyrolisis oil (temperature $300^{\circ} \mathrm{C}$ ) and the most wasteful is 9.02 minutes fueled $100 \%$ oil of pyrolisis.
\end{abstract}

Keywords: pyrolisis, temperature, oil, pp, generator.

\section{PENDAHULUAN}

Sampah plastik di lingkungan masyarakat banyak berasal dari bahan polypropilena (PP). Plastik PP banyak di gunakan sebagai kantong plastik. Namun dibalik kelebihan bahan berbahan plastik terdapat masalah setelah barang tersebut tidak di gunakan. Bahan plastik tidak dapat membusuk,dan tidak dapat diuraikan oleh tanah sehingga menimbulkan masalah baru. Daur ulang limbah plastik merupakan jalan satu-satunya untuk mengurangi jumlah limbah plastik. Namun hanya sedikit bahan plastik yang dapat di 
daur ulang, dan hasil dari daur ulang memiliki kualitas yang rendah sehingga metode ini dirasa tidak efektif.

Selama ini sumber bahan bakar yang banyak digunakan dalam kehidupan sehari-hari berasal dari fosil. Seperti yang kita ketahui sumber bahan bakar yang berasal dari fosil jika di gunakan terus menerus jumlahnya akan smakin menipis. Sebenarnya limbah plastik berpotensi memiliki nilai ekonomis yang tinggi jika diolah dengan cara yang tepat, limbah plastik dapat dimanfaatkan sebagai bahan bakar alternatif.

Seperti yang kita ketahui, limbah plastik menjadi ancaman yang serius untuk lingkungan tempat tinggal kita, maka penulis membuat alat untuk mendaur ulang sampah plastik dengan metode Pirolisis yang menghasilkan minyak bahan bakar alternative. Proses pirolisis adalah teknik pembakaran sampah tanpa $\mathrm{O}_{2}$ dan dilakukan pada suhu $200^{\circ} \mathrm{C}$ sampai $500^{\circ} \mathrm{C}$. Proses ini dapat di katakana sebagai metode ramah lingkungan, karena proses akhir dari metode ini adalah minyak setara bahan bakar yang berasal dari fosil.

Polypropylene (PP) merupakan plastikpolimer yang mudah dibentuk ketika panas,rumus molekulnya adalah $\left(-\mathrm{CHCH}_{3}-\mathrm{CH}_{2}\right)$ n. Yang lentur, keras dan resisten terhadap lemak. Plastik jenis PP dapat dijumpai pada wadah makanan, botol obat, tutup botol, packing/pembungkus makanan kering/snack, sedotan plastik, kantong obat, penutup, cup plastik, tas, botol, dll [8], yang dipotong potong berbentuk cacahan. Dicuci bersih kemudian dikeringkan, dan siap untuk diproses selanjutnya.

Proses perekahan PP merupakan salah satu cara untuk menangani limbah plastik dari semua jenis, jenis perekahan ada 3 macam antara lain : hydrocracking yaitu perekahan menggunakan hidrokgen, thermal cracking yaitu perekahan menggunakan temperatur tinggi, catalyc cracking perekahan menggunakan katalis [7].

Hasil pirolisis yang berupa minyak tersebut akan digunakan untuk menghidupkan generator, dengan catatan harus masih menggunakan perbandingan antara bahan bakar premium dengan bahan bakar hasil proses pirolsis plastik PP tersebut.

Strategi yang dikembangkan dalam penelitian ini adalah bagaimana menghasilkan energy terbarukan yang ramah lingkungan, bersumber dari limbah yang belum maksimal pengolahannya, yaitu sampah plastik diolah menjadi minyak dengan cara pyrolisis. Kelebihan dari proses pirolisis adalah dapat bekerja pada tekanan atmosfir.

\section{METODOLOGI PENELITIAN}

\subsection{Pyrolisis}

Pyrolisis adalah dekomposisi termokimia bahan organik melalui proses pemanasan tanpa atau sedikit oksigen atau pereaksi kimia lainnya, di mana material mentah akan mengalami pemecahan struktur kimia menjadi fase gas [2]. Variasi temperature untuk pengujian adalah sebagai beriku : temperatur reaktor $300^{\circ} \mathrm{C}, 350^{\circ} \mathrm{C}$ dan $400^{\circ} \mathrm{C}$.

\subsection{Alat Dan Urutan Pengujian}

Reaktor berbentuk tabung diameter $40 \mathrm{~cm}$ dan tinggi total $60 \mathrm{~cm}$ seperti yang terlihat pada gambar 1, pendinginan gas menggunakan air yang dilewatkan dalam pipa dan menggunakan sistem kondensasi. Energy panas berasal dari burner berbahan bakar minyak. Temperatur reactor $300^{\circ} \mathrm{C}, 350^{\circ} \mathrm{C}$ dan $400^{\circ} \mathrm{C}$. Alat ukur panas menggunakan thermoreader dan thermocouple. Selang minyak pirolisis ini berfungsi untuk mengalirkan gas hasil pirolisis menuju mesin pendingin untuk dikondensasikan dan untuk menghubungkan sambungan antara unit pendingin dengan tempat minyak pirolisis.

Pendingin ini menggunakan pipa yang terbuat dari tembaga yang dibentuk sepiral ke bawah dan dimasukkan ke sebuah tong plastik yang berisi air yang dimodifikasi sedemikian rupa dengan lubang masukan dan lubang keluaran sebagai jalur gas yang ingin dikondensasikan. Setelah dikondensasikan maka gas akan berubah menjadi cairan yang ditampung didalam botol penampung. Pompa air berfungsi mensirkulasikan air dari bak penampung air menuju ke unit pendingin agar air yang terdapat didalam unit pendingin suhunya konstant.

Bahan baku limbah plastik dicuci, kemudian dipotong potong kemudian dicuci lagi dan kemudian dikeringkan. Plastik yang telah dikondisikan tersebut ditimbang sebanyak $3 \mathrm{~kg}$ kemudian dimasukan dalam reactor, yang telah dipanasi awal. 


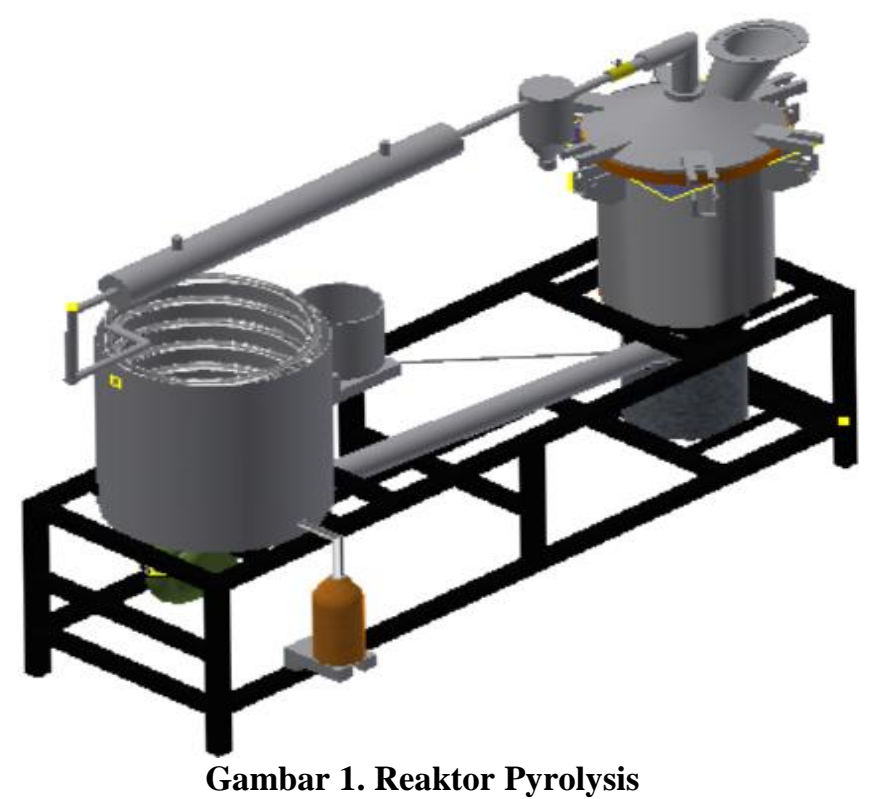

\subsection{Alur Penelitian}

Alur penelitian dapat dilihat di gambar 2, gambar sebagai berikut adalah sebagai berikut :

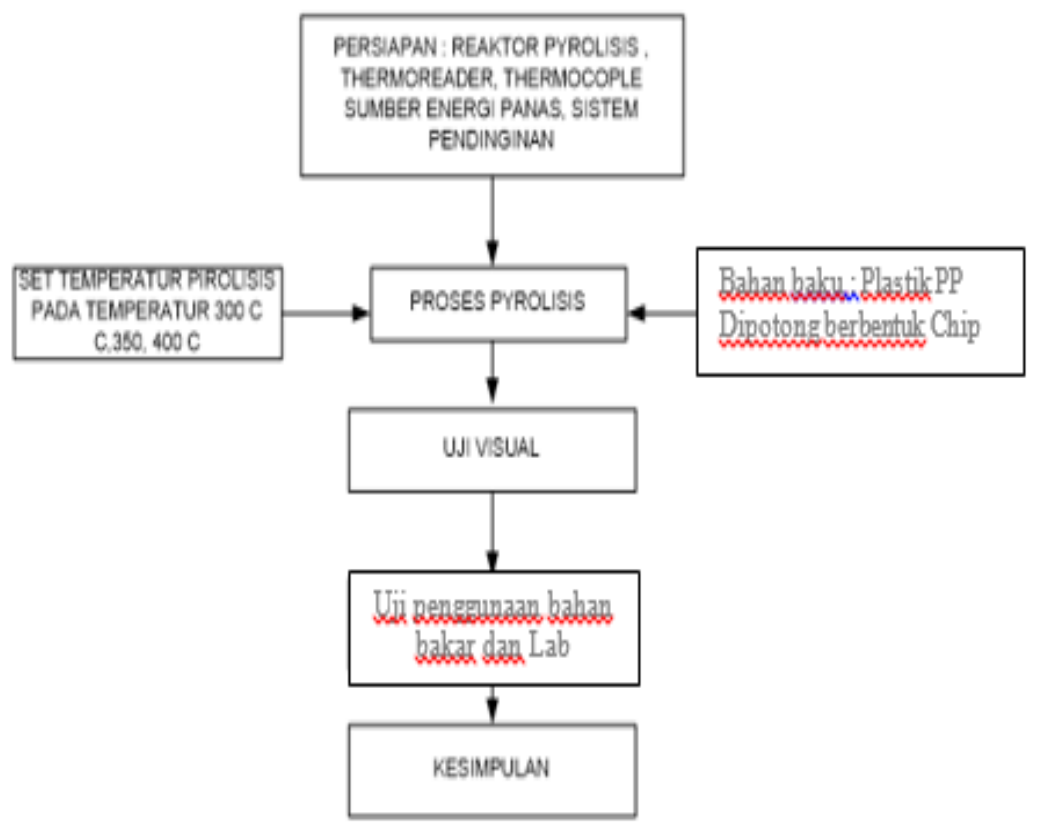

\section{Gambar 2. Alur Penelitian}

\section{HASIL DAN PEMBAHASAN}

Pengujian pyrolysis dengan variasi temperature adalah temperatur reaktor $300{ }^{\circ} \mathrm{C}, 350^{\circ} \mathrm{C}$ dan $400^{\circ} \mathrm{C}$ Hasil pengujian lab mengenai minyak pyrolysis didapat data sebagai berikut : 


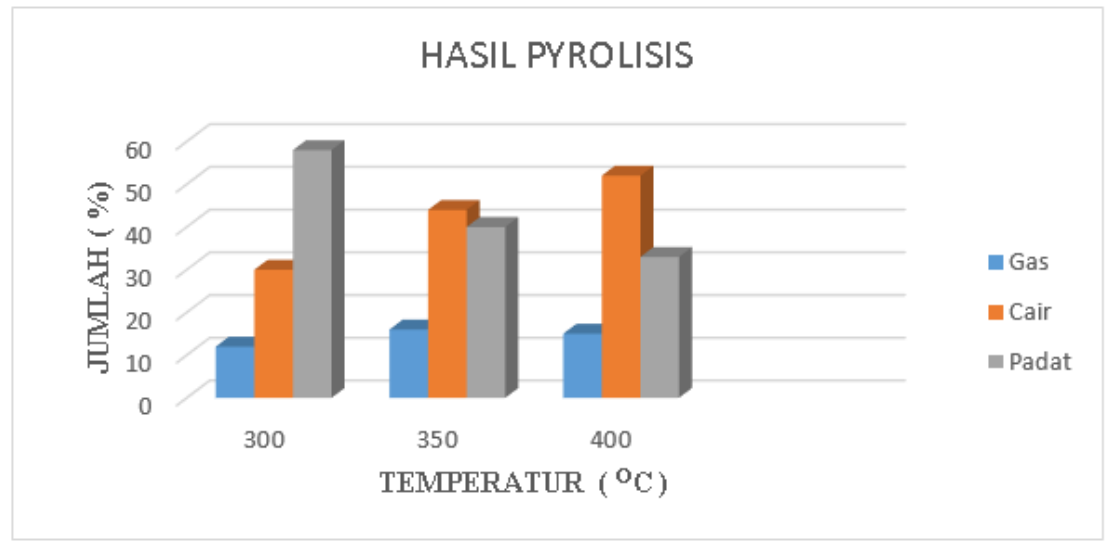

Gambar 3. Hasil Pyrolysis Plastik Jenis PP

Gambar 3 menjelaskan hasil produksi minyak Plastik PP dengan cara pirolisis, temperature reaktor $300^{\circ} \mathrm{C}, 350^{\circ} \mathrm{C}, 400^{\circ} \mathrm{C}$, didapatkan hasil sebagai berikut : hasil pyrolysis plastik PP didapat jumlah minyak yang diperoleh pada temperature reactor $300^{\circ} \mathrm{C}$ paling sedikit berwarna bening jumlah sisa padatan lebih banyak dibandingkan pada temperature reactor $400 \mathrm{oC}$ jumlah minyak lebih banyak warna minyak keruh jumlah sisa padatan lebih sedikit Hasil pengujian lab mengenai minyak pyrolysis didapat data sebagai berikut : Pyrolisis pada suhu rendah plastik PP akan menghasilkan minyak sedikit. Plastik PP memiliki struktur ikatan kristal teratur, lebih sulit terdekomposisi jika dibandingkan dengan plastik PE yang memiliki struktur rantai yang panjang dan bercabang. Hasil pengujian didapat bahwa pada suhu 4000C jumlah minyak, gas, dan padatan yang dihasilkan berturut-turut sebesar $52 \%$, , $15 \%$ dan $33 \%$. Minyak yang dihasilkan lebih banyak dibandingkan dengan temperature reactor 200 OC. Hasil pada suhu 2000C jumlah minyak, gas, dan padatan yang dihasilkan berturut-turut sebesar 30\%, 10\%, dan $60 \%$. Semakin tinggi suhu reaktor dihasilkan minyak pyrolysis dengan kekentalan yang lebih tinggi, kekentalan minyak pyrolysis temperature reaktor $400^{\circ} \mathrm{C}$ yaitu sebesar $3,4 \mathrm{~mm}^{2} / \mathrm{S}$. Warna minyak hasil pyrolysis temperature $400{ }^{\circ} \mathrm{C}$ lebih keruh dibandingkan temperature $300^{\circ} \mathrm{C}$ dan $350{ }^{\circ} \mathrm{C}$.

Tabel 1. Properties minyak pyrolisis plastic

\begin{tabular}{cll}
\hline No & \multicolumn{1}{c}{ Properties } & \multicolumn{1}{c}{ Value } \\
\hline 1 & Density & $74 \mathrm{Kg} / 1$ \\
2 & Viscosity & $1,117 \mathrm{~mm}^{2} / \mathrm{S}$ \\
3 & Flash Point & $22^{\circ} \mathrm{C}$ \\
4 & Calorie & $46,47 \mathrm{~mJ} / \mathrm{kg}$ \\
\hline
\end{tabular}

Tabel 1 adalah prertis minyak pirolisis plastik, nilai kalor dari minyak pirolisis hampir sama dengan nilai kalor minyak tanah yaitu sebesar $43 \mathrm{MJ} / \mathrm{kg}$. Sedangkan kalor tertinggi dari minyak pirolisis yaitu sebesar 46,47 MJ/kg hampir mendekati nilai kalor dari bensin yang memiliki nilai kalor sebesar 47,3 $\mathrm{MJ} / \mathrm{kg}$ (Warrington ,1994). Viscosity sebesar $1,117 \mathrm{~mm}^{2} / \mathrm{S}$ Flash point $22^{\circ} \mathrm{C}$. Pengujian minyak hasil dari pyrolysis plastic untuk bahan bakar generator didapat hasil seperti yang ditunjukkan pada gambar 4 .

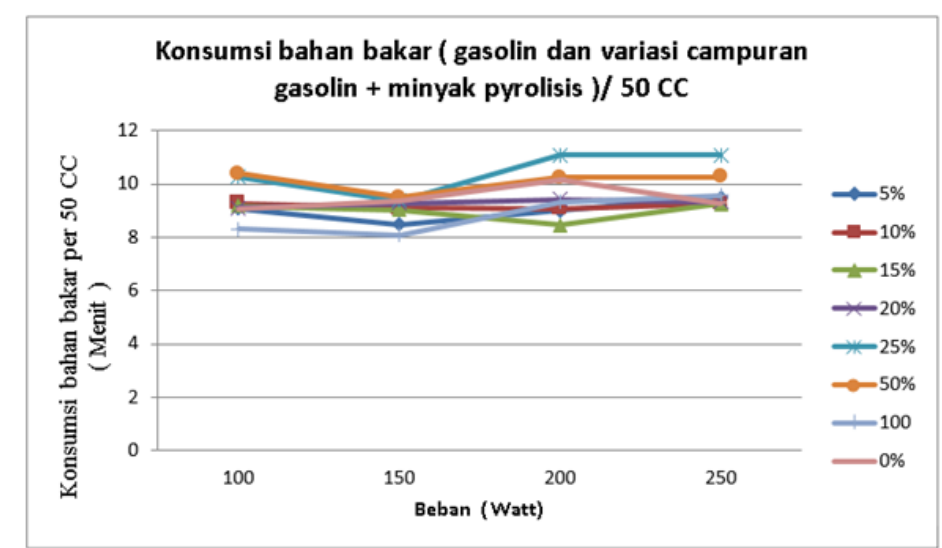

Gambar 4. Hasil Pengujian Beban Generator, Minyak Pyrolysis Temperature $300^{\circ} \mathrm{C}$ 
Gambar 4 adalah grafik hasil pengujian bahan bakar minyak hasil pyrolysis pada temperature 300 ${ }^{\circ} \mathrm{C}$. dengan variasi campuran bahan bakar gasoline + minyak pyrolysis sebesar $5 \%, 10 \%, 15 \%, 20 \%, 25$ $\%, 50 \%, 100 \%$ dan $0 \%$ ( gasoline murni). Hasil pengujian setiap variasi campuran bahan bakar menghasilkan lama nyala generator yang berbeda beda, volume bahan bakar sebesar $50 \mathrm{CC}$. Konsumsi bahan bakar paling rendah pada beban 100 watt adalah campuran gasolin dan minyak hasil pyroisis pada temperatur reaktor 300 oC sebanyak $25 \%$ volume campuran waktu nyala 8.09 menit.

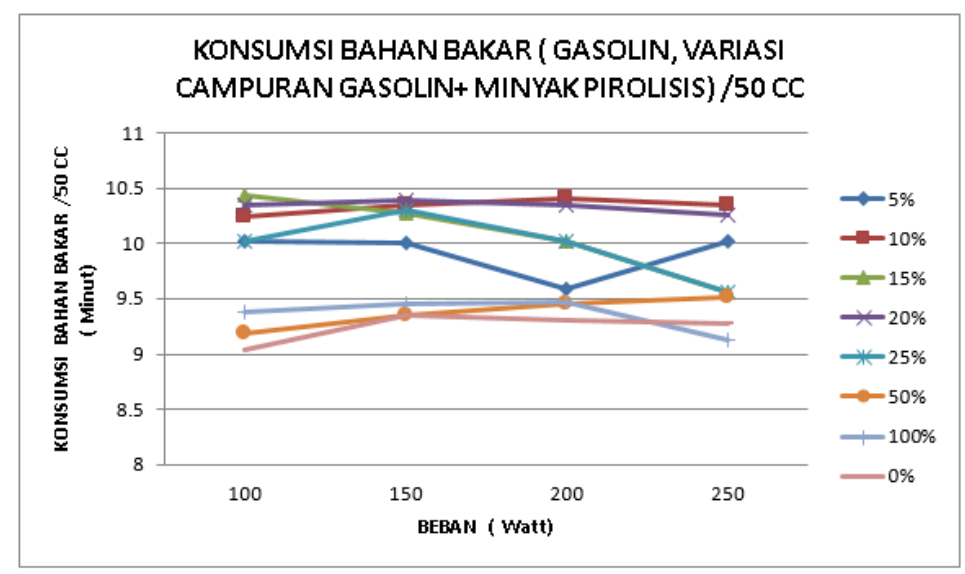

Gambar 5. Hasil Pengujian Beban Generator, Minyak Pyrolysis Temperature $350^{\circ} \mathrm{C}$

Gambar 5 adalah grafik hasil pengujian bahan bakar minyak hasil pyrolysis pada temperature 300 ${ }^{\circ} \mathrm{C}$. dengan variasi campuran bahan bakar gasoline + minyak pyrolysis sebesar $5 \%, 10 \%, 15 \%, 20 \%, 25$ $\%, 50 \%, 100 \%$ dan $0 \%$ ( gasoline murni). Menjelaskan grafik lama waktu pembebanan, waktu paling pendek pada konsumsi bahan bakar paling rendah pada campuran gasolin dan minyak pyrolisis temperatur reaktor 350 oC sebanyak $20 \%$ volume campuran waktu nyala 9,39 menit. Pada variasi campuran yang sama waktu paling lama 10.39 menit.

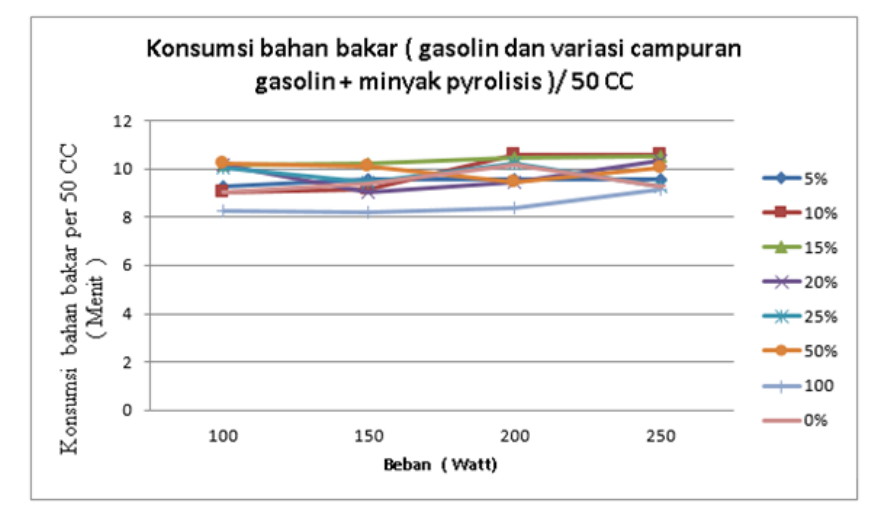

\section{Gambar 6. Hasil Pengujian Beban Generator, Minyak Pyrolysis Temperature $400^{\circ} \mathrm{C}$}

Gambar 6 menjelaskan grafik lama waktu pembebanan, waktu paling pendek pada Konsumsi bahan bakar paling rendah pada campuran gasolin dan minyak pyrolisis temperatur reaktor 400 oC sebanyak $100 \%$ volume campuran waktu nyala 8,02 menit. Pada variasi campuran yang sama waktu paling lama 10.49 menit .Rata- rata waktu penyalaan generator berbahan bakar gasolin adalah 9,35 menit dengan berbagai macam variasi pembebanan.

\section{KESIMPULAN}

Pyrolisis pada suhu rendah plastik PP akan menghasilkan minyak sedikit. Plastik PP memiliki struktur ikatan kristal teratur, lebih sulit terdekomposisi jika dibandingkan dengan plastik PE yang memiliki struktur rantai yang panjang dan bercabang. Hasil pengujian didapat bahwa pada suhu 4000C jumlah minyak, gas, dan padatan yang dihasilkan berturut-turut sebesar 52\%, , 15\% dan $33 \%$. Minyak yang dihasilkan lebih banyak dibandingkan dengan temperature reactor 200 OC. Hasil pada suhu 2000C jumlah minyak, gas, dan padatan yang dihasilkan berturut-turut sebesar 30\%, 10\%, dan $60 \%$. Rata- rata 
waktu penyalaan generator berbahan bakar gasolin adalah 9,25 menit dengan berbagai macam variasi pembebanan. konsumsi bahan bakar paling rendah pada beban 100 watt adalah campuran gasolin dan minyak hasil pyroisis pada temperatur reaktor $300 \mathrm{oC}$ sebanyak $25 \%$ volume campuran waktu nyala 8.09 menit. Pada variasi campuran yang sama waktu paling lama 11.09 menit. Waktu paling pendek pada konsumsi bahan bakar paling rendah pada campuran gasolin dan minyak pyrolisis temperatur reaktor 350 oC sebanyak $20 \%$ volume campuran waktu nyala 9,39 menit. Pada variasi campuran yang sama waktu paling lama 10.39 menit Waktu paling pendek pada Konsumsi bahan bakar paling rendah pada campuran gasolin dan minyak pyrolisis temperatur reaktor $400 \mathrm{oC}$ sebanyak $100 \%$ volume campuran waktu nyala 8,02 menit. Pada variasi campuran yang sama waktu paling lama 10.49 menit .Rata- rata waktu penyalaan generator berbahan bakar gasolin adalah 9,35 menit dengan berbagai macam variasi pembebanan.

\section{UCAPAN TERIMA KASIH}

Terima kasih kepada Kementrian Ristek dikti, penelitian ini dibiayai lewat hibah penelitian terapan tahun 1 tahun pelaksanaan 2017. No kontrak : 161-2/A/Puslit/ATW/VII/2017 dan kepada LPPM AT Warga Surakarta yang telah mendukung pelaksanaan penelitian hibah terapan 2017.

\section{DAFTAR PUSTAKA}

[1] Arif Setyo Nugroho, Rahmad, 2017, Pemanfaatan Sampah Padat Kota Menjadi Energi Alternative, Pr osiding SNATI F Ke - 4 , ISBN: 978-602-1180-50-1

[2] Endang K, Muhtar G,Abed Nego,FX Angga Sugiyana,2016, Pengolahan Sampah Plastik dengan Methoda Pirolisis Menjadi Bahan Bakar Minyak, Prosiding seminar Nasional Teknik Kimia “" Kejuangan", ISSN 1693-4393

[3] Guntur, R., Kumar, D. dan Reddy, V.K.,2011, Experimental Evaluation of A Diesel Engine with Blends of DieselPlastic Pyrolysis Oil, International Journal of Engineering Science and Technology (IJEST) Vol. 3 No. 6.

[4] Kadir , 2012, Kajian pemanfaatan Sampah Plastik sebagai Sumber Bahan Bakar cair, Dinamika, ISSN 2085-8817.

[5] Kumar S, Panda, AK dan Sing RK, 2011, A review on Tertiary Recycling of High - Density polyethylene to Fuel, resources, Conservation and Recycling Vol 55 893-910.

[6] Mohamad Syamsiro,Saptoadi, Norsujianto, Cheng S, Zainal,Yoshikawa.K, 2014, Fuel Oil Production From Municipal Plastic Waste in squential Pyrolisis and catalytic Reforming reactors, Energy Procedia 47, pp. 180-188.

[7] Panda K A Sing, Mishra, 2010, Thermolysis of waste plastic to liquid fuel a suitable methode for plastic waste management and manufacture of value added products- A World Prospective, renewable and sustainable energy reviews 14, 233-248

[8] Suharto, 2010, Rancangan Produk Bahan Plastik Daur Ulang sebagai Upaya Peningkatan Industri Kreatif. Jurnal Politeknik Negri Semarang. Jawa Tengah.

[9] Untoro Budi Sarono,2013, Berbagai Metode Konversi sampah Plastik menjadi bahan bakar Minyak, Jurnal teknik ISSN 20088-3676 Vol 3 No1.

[10] Paradela Filipe, et al, 2009. Journal of Analytical and Applied Pyrolysis. Estrada do Panco do Luminar. Lisboa. Portugal

[11] Warrington, 1994, Analysis Project Department of the Environment, National Household Waste, UK 